\title{
Effects of Post-Deposition Annealing Atmosphere and Duration on Sol-Gel Derived Amorphous Indium-Zinc-Oxide Thin Film Transistors
}

\author{
Wan-Fang Chung ${ }^{a}$, Ting-Chang Chang ${ }^{\mathrm{b}, \mathrm{c}}$, Hung-Wei Li ${ }^{\mathrm{d}}$, Tseung-Yuen Tseng ${ }^{\mathrm{a}}$, Ya- \\ Hsiang Tai ${ }^{\mathrm{e}}$ \\ a Department of Electronics Engineering \& Institute of Electronics, National Chiao Tung \\ University, Hsinchu 300, Taiwan, R.O.C. \\ ${ }^{\mathrm{b}}$ Department of Physics, National Sun Yat-Sen University, Kaohsiung 804, Taiwan, \\ R.O.C. \\ c Center for Nanoscience \& Nanotechnology, National Sun Yat-Sen University, \\ Kaohsiung 804, Taiwan, R.O.C. \\ d Department of Photonics \& Institute of Electro-Optical Engineering, National Chiao \\ Tung University, Hsinchu 300, Taiwan, R.O.C. \\ ${ }^{\mathrm{e}}$ Department of Photonics \& Display Institute, National Chiao Tung University, Hsinchu \\ 300, Taiwan, R.O.C.
}

This work shows the effects of post-deposition annealing atmosphere and duration on the properties of sol-gel derived amorphous indium zinc oxide thin film transistors ( $a$-IZO TFTs). Two different post-deposition annealing atmospheres, nitrogen and oxygen, were used in this study. Experimental results showed that the $\mathrm{O}_{2}$-annealed devices showed better electrical characteristics than the $\mathrm{N}_{2}$-annealed samples. Under $\mathrm{O}_{2}$-annealing, field effect mobility was enhanced to $1.47 \mathrm{~cm}^{2} / \mathrm{V} \mathrm{s}$, the threshold voltage increased to $-4.61 \mathrm{~V}$ and the subthreshold swing improved to 0.86 $\mathrm{V} /$ dec. Also, the transfer characteristics of $a$-IZO TFTs improve with annealing time. X-ray photoelectron spectroscopy (XPS) analysis indicated that the chemical composition of the IZO film was modified by the oxygen annealing.

\section{Introduction}

Recently, zinc oxide ( $\mathrm{ZnO}$ )-based materials, such as $\mathrm{ZnO}$, indium zinc oxide (IZO), and indium gallium zinc oxide (IGZO), have been extensively investigated as active channel layers in thin film transistors (TFTs) (1-3). These are generally called oxide TFTs, and are studied for use in optoelectronic electronics such as active matrix organic lightemitting diodes (AMOLED) and active matrix liquid crystal displays (AMLCD) due to their potential low cost applications and large area deposition $(4,5)$. Previous studies have demonstrated that the oxide TFTs show better device performance and reliability compared to a-Si TFTs, and excellent uniformity of channel material compared to poly-Si TFTs $(6,7)$. Currently, oxide TFTs are mainly produced by vacuum systems such as radio frequency (RF) magnetron sputtering and pulsed laser deposition (PLD) $(8,9)$. However, vacuum-deposition methods require expensive equipment and therefore entail high manufacturing costs. Considering the simplicity, low cost, and high throughput of highperformance electronics fabrication, solution-processed thin-film deposition methods, 
including sol-gel and spray pyrolysis, are also currently utilized (10-13). These TFTs generally work in $n$-channel mode. Among the available amorphous oxide semiconductors, IZO generally can obtain higher field effect mobility $\left(\mu_{\text {eff }}\right)(14)$. Thus, numerous publications about IZO TFTs have recently been reported.

\section{Motivation}

To retain the stability of the active channel layer, a co-planar type bottom gate TFT structure is usually adopted. This structure can prevent the active layer from deterioration by the subsequent gate insulator deposition and gate electrode manufacturing processes in top gate TFTs. However, the property of IZO thin film is unstable such that postdeposition annealing of the active layer is inevitable in $a$-IZO TFT fabrication. Although the characteristics of oxide TFTs have recently been explored, a detailed study of their properties in relation to post-deposition annealing conditions and chemical composition has not been reported from the viewpoint of semiconductor materials (15-17). This study reports the post-deposition annealing effects on $a$-IZO TFTs and discusses the chemical composition of the IZO thin film. Longer annealing in $\mathrm{O}_{2}$ ambience improved the field effect mobility $\left(\mu_{\text {eff }}\right)$, the threshold voltage $\left(V_{\mathrm{t}}\right)$ and the subthreshold swing (S.S.).

\section{Experimental Procedure}

Co-planar type bottom gate $a$-IZO TFTs were prepared, and the schematic diagram of the fabricated TFT is shown in Fig. 1. After a $100 \mathrm{~nm}$ molybdenum tungsten (MoW) layer was deposited on glass substrate as gate electrode, a $300 \mathrm{~nm}$ thick silicon nitride $\left(\mathrm{Si}_{3} \mathrm{~N}_{4}\right)$ film was deposited as an insulator layer. Indium tin oxide (ITO) was deposited by RF sputtering and served as source and drain electrodes. Finally, a $30 \mathrm{~nm}$ thick IZO thin film was deposited as the active layer by spin-coating at room temperature and atmospheric pressure, and then baked in a furnace at $500{ }^{\circ} \mathrm{C}$ for $1 \mathrm{hr}$ to improve the film quality. It was subsequently patterned by photolithography and wet etching. The precursor solution for IZO films was synthesized by dissolving $0.1 \mathrm{M}$ of zinc acetate dihydrate $\left[\mathrm{Zn}\left(\mathrm{CH}_{3} \mathrm{COO}\right)_{2} \cdot 2 \mathrm{H}_{2} \mathrm{O}\right]$ and $0.1 \mathrm{M}$ of indium acetate $\left[\mathrm{In}\left(\mathrm{CH}_{3} \mathrm{COO}\right)_{3}\right]$ in 2methoxyethanol (2-ME) at $50{ }^{\circ} \mathrm{C}$. Stabilizing agents for dissolution and formation of stable sol-gel is required, due to the solubility of $\mathrm{Zn}\left(\mathrm{CH}_{3} \mathrm{COO}\right)_{2} \cdot 2 \mathrm{H}_{2} \mathrm{O}$ and $\mathrm{In}\left(\mathrm{CH}_{3} \mathrm{COO}\right)_{3}$. A precursor solution of $\mathrm{Zn}\left(\mathrm{CH}_{3} \mathrm{COO}\right)_{2} \cdot 2 \mathrm{H}_{2} \mathrm{O}$ with limited solubility in alcohols is easily precipitated or gelled, while $\operatorname{In}\left(\mathrm{CH}_{3} \mathrm{COO}\right)_{3}$ is not soluble in 2-ME. Both $0.4 \mathrm{M}$ of Diethanolamine (DEA) and $0.4 \mathrm{M}$ of acetylacetone were utilized to stabilize the IZO precursor solution $(18,19)$. The channel width and length of all $a$-IGZO TFTs were 500 $\mu \mathrm{m}$ and $50 \mu \mathrm{m}$, respectively. Post-deposition annealing was performed at $300{ }^{\circ} \mathrm{C}$ by an atmospheric annealing furnace with $\mathrm{N}_{2}$ or $\mathrm{O}_{2}$ gas flow of $10 \mathrm{~L} / \mathrm{sec}$. All Current-Voltage (I-V) characteristics of IZO TFTs were measured by an Agilent 4156C semiconductor parameter analyzer in the dark at room temperature. Chemical compositions of annealedIZO films were analyzed by X-ray Photoelectron Spectroscopy (XPS). The effects of the annealing condition on $a$-IZO TFTs were examined. 


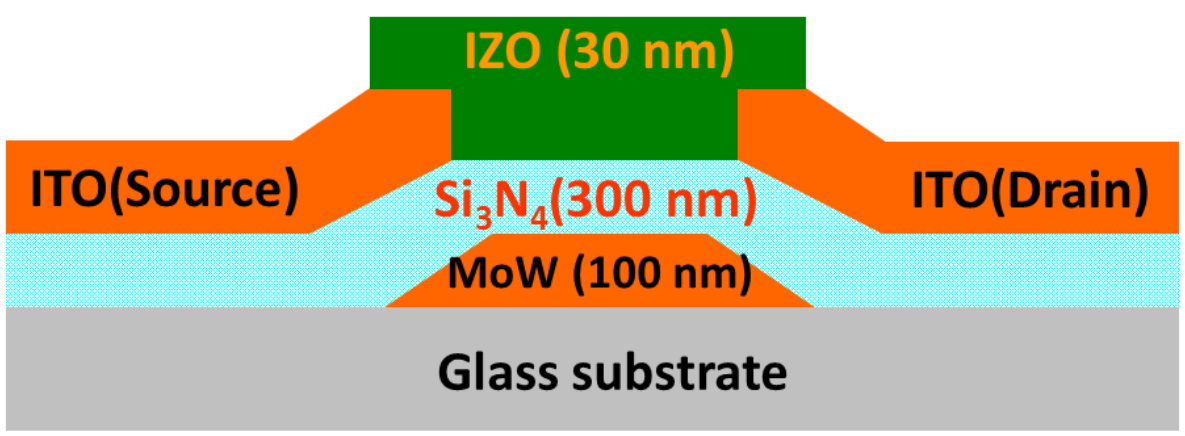

Figure 1. Schematic image of fabricated amorphous indium zinc oxide thin film transistor (a-IZO TFT).

\section{$\underline{\text { Results and Discussion }}$}

To eliminate possible unintentional doping of the semiconductor due to oxygen deficiencies, $a$-IZO TFTs were annealed at temperature of $300{ }^{\circ} \mathrm{C}$ for $30 \mathrm{~min}$. Different post-deposition annealing environments significantly affected the transfer characteristics, as shown in Fig. 2. The as-deposited IZO TFTs exhibit normally-on characteristics, originating from the fact that the IZO films contain many carriers due to a relatively large nonstoichiometric chemical composition, i.e., oxygen vacancies $(20,21)$. After the postdeposition annealing in $\mathrm{O}_{2}$ and $\mathrm{N}_{2}$ was performed, the device appeared to switch characteristics. The quality of the gate insulator layer, $\mathrm{SiN}_{\mathrm{x}}$, was not damaged by thermal annealing, and the gate leakage current did not demonstrate any remarkable change (data not shown). The field effect mobility, subthreshold swing and threshold voltage of $\mathrm{O}_{2}$ annealed TFTs were clearly improved, compared with $\mathrm{N}_{2}$-annealed TFTs. The $\mathrm{O}_{2}-$ annealed TFTs exhibited $\mu_{\text {eff }}$ of $1.19 \mathrm{~cm}^{2} / \mathrm{V} \mathrm{s}, V_{\mathrm{t}}$ of $-6.77 \mathrm{~V}$, S.S. of $1.08 \mathrm{~V} / \mathrm{dec}$, and an on-off current ratio $\left(\mathrm{I}_{\text {on }} / \mathrm{I}_{\text {off }}\right)$ of more than $10^{6}$.

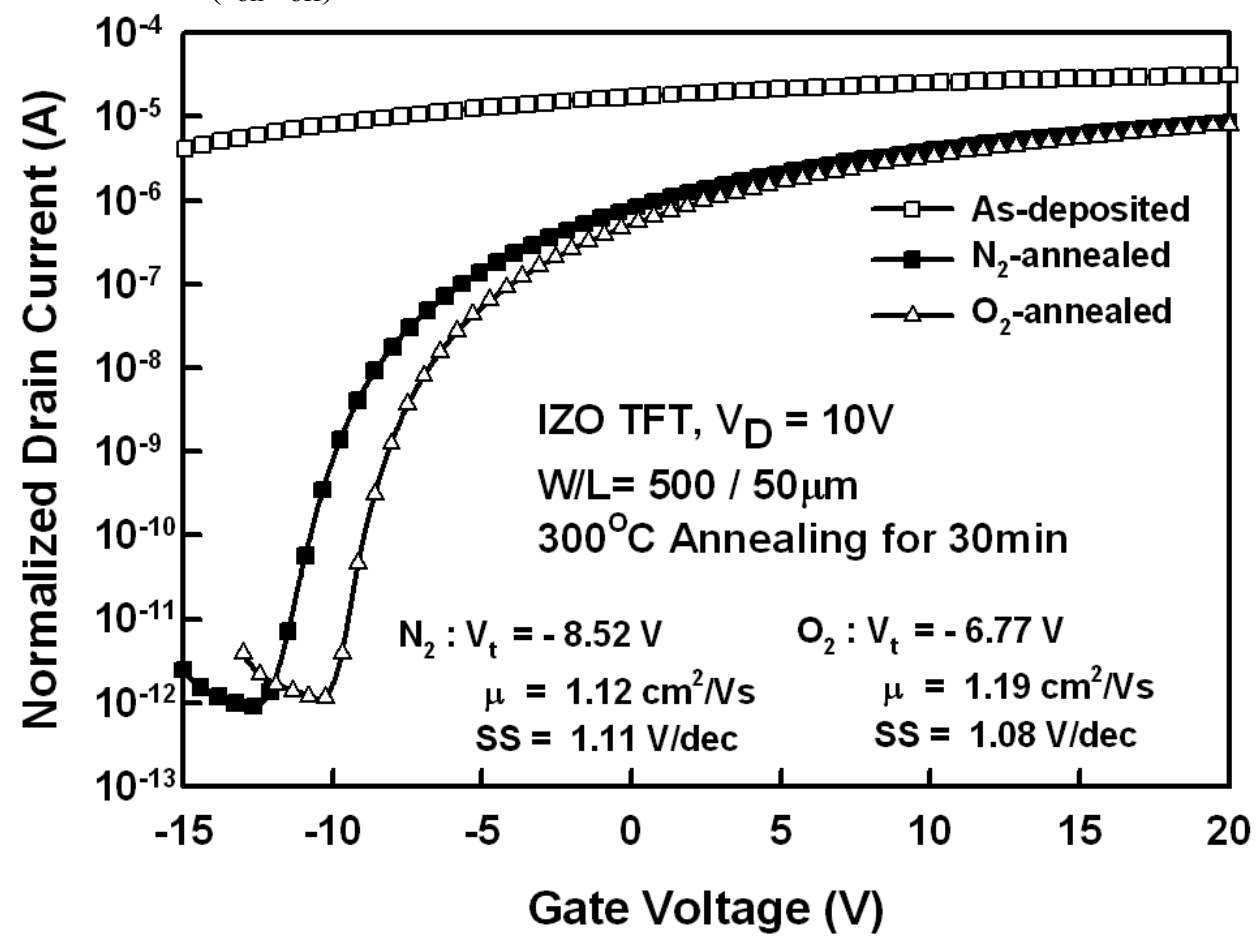

Figure 2. $I_{d}-V_{g}$ plots of as-deposited, $\mathrm{N}_{2}$-annealed and $\mathrm{O}_{2}$-annealed TFTs at $\mathrm{V}_{\mathrm{D}}=10 \mathrm{~V}$. 
Since oxygen annealing is clearly a better annealing atmosphere for the active layer of IZO TFTs, the effects of $\mathrm{O}_{2}$-annealing time was further investigated. Fig. 3 and Table 1 present the transfer characteristics and the extracted electrical parameters of IZO TFTs, annealed in oxygen environment at $300{ }^{\circ} \mathrm{C}$ for different durations. Fig. 3 shows that the threshold voltage increases as the annealing time increases. In addition, the mobility and the subthreshold swing were also enhanced. This is due to decreasing oxygen vacancies and lower defect density at interface or in the bulk. The parameters of the devices with different annealing times are listed in Table 1 . The a-IZO TFTs $\mathrm{O}_{2}$-annealed for $90 \mathrm{~min}$ have better electrical characteristics. When the annealing time increased from 30 to 90 min, the threshold voltage increased from -6.77 to $-4.61 \mathrm{~V}$, mobility increased from 1.19 to $1.47 \mathrm{~cm}^{2} / \mathrm{V} \mathrm{s}$, and subthreshold swing decreased from 1.86 to $0.86 \mathrm{~V} / \mathrm{dec}$.

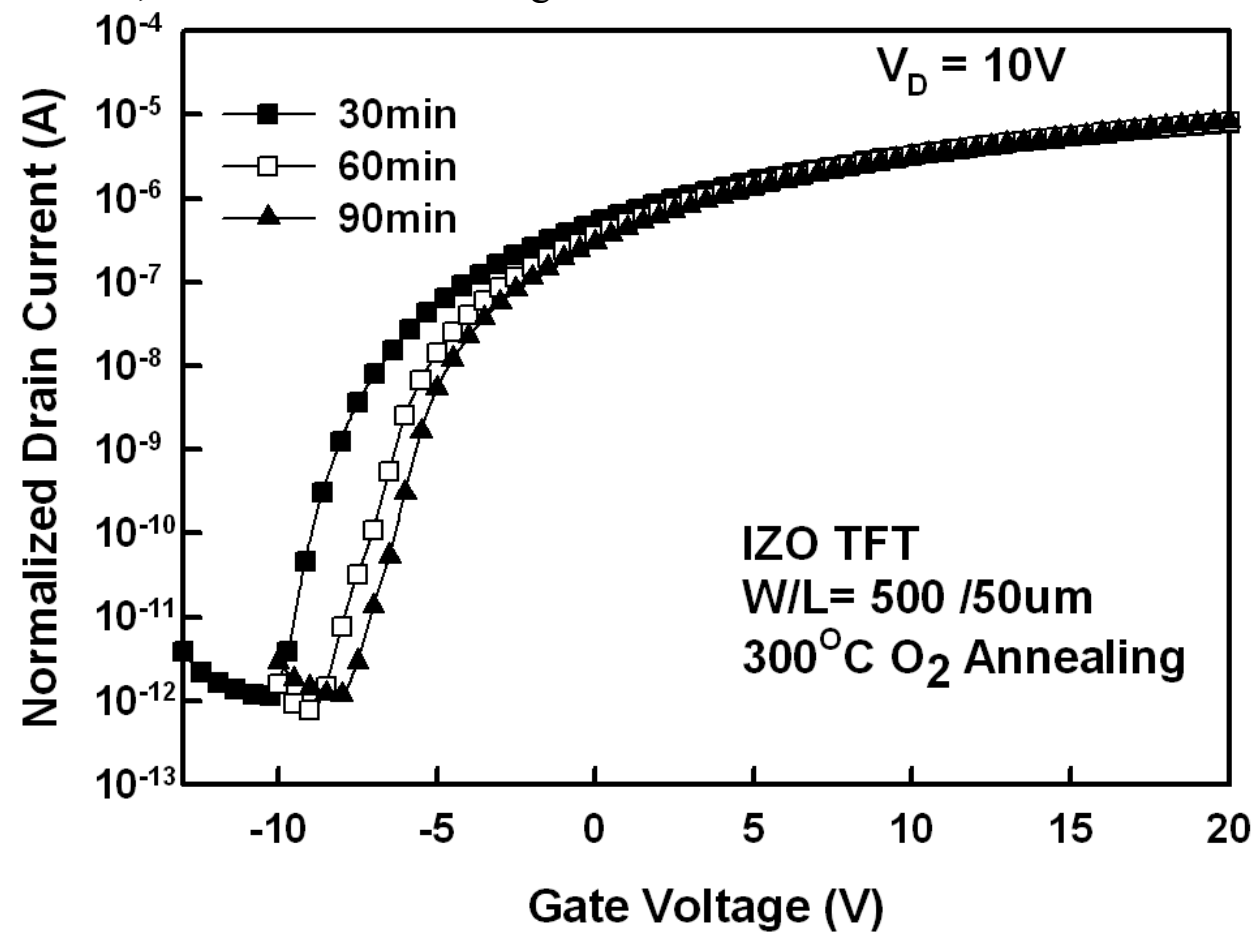

Figure 3. $I_{d}-V_{g}$ plots of $300{ }^{\circ} \mathrm{C} \mathrm{O}_{2}$-annealed TFTs of $30 \mathrm{~min}, 60 \mathrm{~min}$ and $90 \mathrm{~min}$ annealing duration.

TABLE I. Electrical property evolution with annealing time in oxygen atmosphere for the fabricated aIZO TFTs.

\begin{tabular}{|c|c|c|c|}
\hline Annealing Time (min) & $\boldsymbol{V}_{\mathbf{t}}(\mathbf{V})$ & $\boldsymbol{\mu}\left(\mathbf{c m}^{2} / \mathbf{V ~ s}\right)$ & $\boldsymbol{S S} \mathbf{( V / d e c )}$ \\
\hline 30 & -6.77 & 1.19 & 1.08 \\
\hline 60 & -5.25 & 1.38 & 0.90 \\
\hline 90 & -4.61 & 1.47 & 0.86 \\
\hline
\end{tabular}

X-ray photoelectron spectroscopy (XPS) was conducted to analyze the chemical bonding state of zinc, indium, and incorporated oxygen in IZO thin films. Because the Zn and In XPS peaks exhibited no shift behavior in binding energy, only the incorporated oxygen peak is shown in Fig. 4. Earlier investigations stated that the binding energy of oxygen 1s (O 1s) located at near $532.30 \mathrm{eV}$ usually originates from the presence of loosely bound oxygen on the surface of IZO film belonging to a specific specie, e.g., $\mathrm{CO}_{3}$ or adsorbed $\mathrm{H}_{2} \mathrm{O}$ or adsorbed $\mathrm{O}_{2}$ (22-28). The binding energy at $531.51 \mathrm{eV}$ is associated with $\mathrm{O}^{2-}$ ions that are in oxygen deficient regions of the IZO film. Therefore, the intensity of variation of this component may be related to oxygen vacancy 
concentration. The component on the low binding energy side of the $\mathrm{O} 1 \mathrm{~s}$ spectrum at $530.35 \mathrm{eV}$ is associated with $\mathrm{O}^{2-}$ ions surrounded by $\mathrm{Zn}$ and In atoms in the IZO compound system. This indicates that the intensity of this component is a measure of the amount of oxygen atoms in a fully oxidized stoichiometric atmosphere.

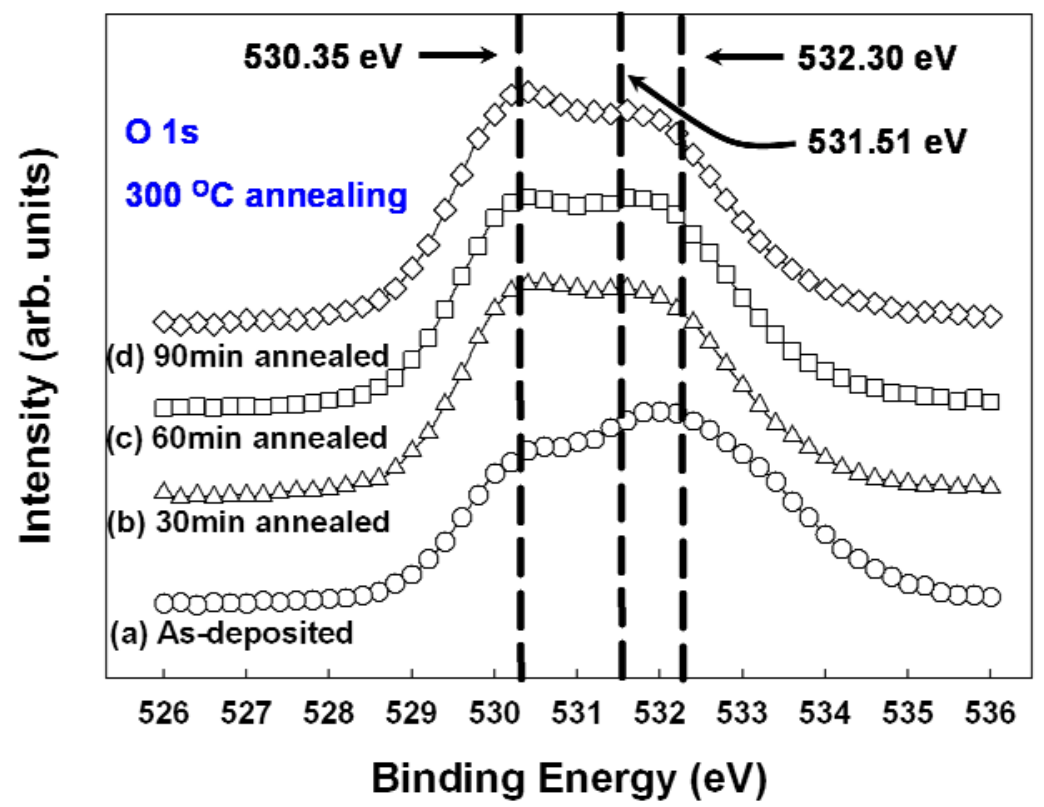

Figure 4. X-ray photoelectron spectroscopy data of (a) as-deposited a-IZO thin film, (b) $30 \mathrm{~min}$, (c) $60 \mathrm{~min}$, and (c) $90 \mathrm{~min}$-annealed thin films at $300{ }^{\circ} \mathrm{C}$.

According to Fig. 4, the oxygen deficiency-related peak and the loosely-bounded oxygen peak from the XPS data of the as-deposited sample are larger than the $\mathrm{Zn}-\mathrm{O}$ bonding peak. After the post-deposition annealing at $300{ }^{\circ} \mathrm{C}$, XPS analysis revealed a diminishing oxygen vacancy contribution to carrier concentration with an increase of $\mathrm{Zn}$ $\mathrm{O}$ bonding peak intensity. The decrease of the oxygen deficiency-related peak infers that the oxygen vacancies of IZO films are reduced because the surface has compensated with $\mathrm{O}$ atoms (29). For incremental annealing time, more $\mathrm{Zn}$ atoms bond with oxygen ( $\mathrm{Zn}-\mathrm{O})$ and oxygen vacancies $\left(\mathrm{V}_{\mathrm{O}}\right)$ become fewer. The decrease of oxygen vacancies and the $\mathrm{Zn}$ $\mathrm{O}$ re-bonding improve the film quality both at the interface and in bulk. Based on these factors, the device should have more positive threshold voltage value and better mobility and subthreshold swing. These hypotheses are consistent with the TFT parameters we have extracted.

\section{$\underline{\text { Conclusion }}$}

The effects of post-deposition annealing atmosphere and duration on a-IZO TFTs have been investigated by electrical measurement and material analysis. Compared with $\mathrm{N}_{2}$-annealed TFTs, $\mathrm{O}_{2}$-annealed TFTs show better performance, with $\mu_{\text {eff }}$ as high as 1.47 $\mathrm{cm}^{2} / \mathrm{V} \mathrm{s}, V_{T}$ of $-4.61 \mathrm{~V}$, S.S. of $0.86 \mathrm{~V} / \mathrm{dec}$ and an on-off current ratio $\left(\mathrm{I}_{\mathrm{on}} / \mathrm{I}_{\mathrm{off}}\right)$ of more than $10^{6}$ as annealing time was prolonged. XPS data confirms that oxygen modified the chemical composition of the IZO channel layer during the post-treatment. Oxygen vacancies, which acted as n-type dopants in IZO material, were reduced by $\mathrm{O}_{2}$-annealing, resulting in better device performance $(30,31)$. Thus, a thermal annealing process conducted in an oxygen-rich atmosphere can greatly reduce the oxygen vacancy 
concentration in IZO samples through oxygen surface passivation. Longer annealing decreased the oxygen defects, thus resulting in an increase of carrier mobility and conductivity. In summary, the annealing process can repair the defects both at the interface and in the bulk and decrease oxygen vacancy in IZO thin films, improving the threshold voltage, field-effect mobility and subthreshold swing. In order to obtain better performance, it is necessary to use an $\mathrm{O}_{2}$-rich environment and longer post-deposition annealing time.

\section{Acknowledgments}

This work was performed at National Science Council Core Facilities Laboratory for Nano-Science and Nano-Technology in Kaohsiung-Pingtung area and was supported by the National Science Council of the Republic of China under Contract Nos. NSC-992120-M-110-001 and NSC 97-2112-M-110-009-MY3.

\section{References}

1. E. M. C. Fortunato, P. M. C. Barquinha, A. M. B. G. Pimentel, A. M. F. Gonçalves, A. J. S. Marques, R. F. P. Martins, and L. M. N. Pereira, Appl. Phys. Lett., 85, 2541 (2008).

2. N. L. Dehuff, E. S. Kettenring, D. Hong, H. Q. Chiang, J. F. Wager, R. L. Hoffman, C. H. Park, and D. A. Keszler, J. Appl. Phys., 97, 064505 (2005).

3. K. Nomura, H. Ohta, A. Takagi, T. Kamiya, M. Hirano, and H. Hosono, Nature, 432, 488 (2004).

4. R. B. M. Cross, M. M. De Souza, S. C. Deane, and N. D. Young, IEEE Trans. Electron Devices, 55, 1109 (2008).

5. J. Y. Kwon, K. S. Son, J. S. Jung, T. S. Kim, M. K. Ryu, K. B. Park, B. W. Yoo, J. W. Kim, Y. G. Lee, K. C. Park, S. Y. Lee, and J. M. Kim, IEEE Electron Device Lett., 29, 1309 (2008).

6. G. H. Kim, H. S. Shin, B. D. Ahn, K. H. Kim, W. J. Park, and H. J. Kim, J. Electrochem. Soc., 156, H7 (2009).

7. G. H. Kim, H. S. Kim, H. S. Shin, B. D. Ahn, K. H. Kim, and H. J. Kim, Thin Solid Films, 517, 4007 (2009).

8. H. Q. Chiang, J. F. Wager, R. L. Hoffman, J. Jeong, and D. A. Keszler, Appl. Phys. Lett., 86, 013503 (2005).

9. H. Yabuta, M. Sano, K. Abe, T. Aiba, T. Den, H. Kumomi, K. Nomura, T. Kamiya, and H. Hosono, Appl. Phys. Lett., 89, 112123 (2006).

10. B. S. Ong, C. Li, Y. Li, Y. Wu, and R. Loutfy, J. Am. Chem. Soc., 129, 2750 (2007).

11. H. C. Cheng, C. F. Chen, and C. Y. Tsay, Appl. Phys. Lett., 90, 012113 (2007).

12. Y. J. Chang, D. H. Lee, G. S. Herman, and C. H. Chang, Electrochem. Solid-State Lett., 1, H135 (2007).

13. D. H. Lee, Y. J. Chang, G. S. Herman, and C. H. Chang, Adv. Mater. (Weinheim, Ger.), 19, 843 (2007). 
14. H. Hosono, J. Non-Cryst. Solids, 352, 851 (2006).

15. D. Hong, H. Q. Chiang, and J. F. Wager, J. Vac. Sci. Technol. B, 24, L23 (2006).

16. B. Yaglioglu, H. Y. Yeom, and D. C. Paine, Appl. Phys. Lett., 86, 261908 (2005).

17. B. Yaglioglu, H. Y. Yeom, R. Beresford, and D. C. Paine, Appl. Phys. Lett., 89, 062103 (2006).

18. M. L. Mottern, F. Tyholdt, A. Ulyashin, A. T. J. van Helvoort, H. Verweij, and R. Bredesen, Thin Solid Films, 515, 3918 (2007).

19. C. G. Choi, S. J. Seo, and B. S. Bae, Electrochem. Solid-State Lett., 11, H7 (2008).

20. S. Narushima, H. Mizoguchi, K. Shimizu, K. Ueda, H. Ohta, M. Hirano, T. Kamiya, and H. Hosono, Adv. Mater., 15, 1409 (2003).

21. T. Kamiya, S. Narushima, H. Mizoguchi, K. Ueda, H. Ohta, M. Hirano, and H. Hosono, Adv. Funct. Mater., 15, 965 (2005).

22. C. Bae, D. Kim, S. Moon, T. Choi, Y. Kim, B. S. Kim, J.-S. Lee, H. Shin, and J. Moon, Appl. Materials and Interfaces, 2, 626 (2010).

23. S. M. Park, T. Ikegami, and K. Ebihara, Thin Solid Films, 513, 90 (2006).

24. M. Chen, Z.L. Pei, C. Sun, L.S. Wen, and X. Wang, J. Cryst. Growth, 220, 254 (2000).

25. J. C. C. Fan and J. B. Goodenough, J. Appl. Phys., 48, 3524 (1977).

26. G. H. Kim, H. S. Kim, H.S. Shin, B. D. Ahn, K. H. Kim, and H. J. Kim, Thin Solid Films, 517, 4007 (1996).

27. H. Khallaf, G. Chai, O. Lupan, H. Heinrich, S. Park, A. Schulte and Lee Chow, J. Phys. D, 42, 135304 (2009).

28. S. Kim, H. Moon, D. Gupta, S. Yoo, and Y. K. Choi, IEEE Trans. Electron Devices, 56, 696 (2009).

29. J. Cheng, Y. Zhang, R. Guo, Ferroelectrics, 382, 68 (2009).

30. H. S. Bae, J. H. Kim, and S. Im, Electrochem. Solid-State Lett., 7, G279 (2004).

31. Y. Ma, G. T. Du, T. P. Yang, D. L. Qiu, X. Zhang, H. J. Yang, Y. T. Zhang, B. J. Zhao, X. T. Yang, and D. L. Liu, J. Cryst. Growth, 255, 303 (2003). 